\title{
Soil-Water Separation Property of Bauxite Mine Slime
}

\author{
Zhiqiang WU ${ }^{\mathrm{a}, \mathrm{b}, 1}$, Kai XU ${ }^{\mathrm{a}, \mathrm{b}}$, Zhihuan WANG ${ }^{\mathrm{c}}$, Shuaiheng LI $^{\mathrm{b}}$ and Baoying JIANG ${ }^{\mathrm{b}}$ \\ ${ }^{a}$ State Key Laboratory of Hydrology-Water Resources and Hydraulic Engineering, \\ Nanjing 210029, China \\ ${ }^{\mathrm{b}}$ Nanjing Hydraulic Research Institute, Nanjing 210029, China \\ ' Jiangsu Provincial Hydraulic Research Institute, Nanjing 210017, China
}

\begin{abstract}
Traditional disposal of the high-water content slime from the beneficiating and washing of the bauxite mine requires lots of land and a long time to consolidate, which has attracted a wide range of environmental and social concerns. High-speed centrifugal test was carried out to investigate the water property and composition of high-water content bauxite washing mud. Test results indicated that the bound water content ranged from $29.7 \%$ to $31.4 \%$, free water content ranged from $250.6 \%$ to $252.3 \%$. The bound water accounted for only $11 \%$, while the free water accounted for about $89 \%$ of total water content. A series of model tests were conducted to study the slurry-water separation property of highwater content bauxite mine slime. Experiments showed that controlling the vacuum load application process can effectively inhibit the formation of lowpermeability stratum around the drainage body. The final settlement increased by $31.5 \%$ and the amount of water discharge increased by $39.52 \%$ compared with the conventional vacuum preloading method. Moreover, the water content may decrease from $281.9 \%$ to $53.6 \%$ within 60 hours with the increase of density of drainage body under the controlled vacuum load application process.
\end{abstract}

Keywords. Bauxite, mine slime, soil-water separation, free water, bound water

\section{Introduction}

Alumina output of Guangxi Province ranks No.4 in China, with a huge amount of highwater content slime produced which requires lots of land and a long time to consolidate. About $0.8-1.0$ tons of dry slime or 1.0 to 2.5 tons of wet slime will be discharged for each ton of alumina production according to statistics $[1,2]$, and there will be more and more mud dumps with the increase of alumina production capacity in the process of exploiting karst accumulative bauxite. The suspended solids with particle size less than $1 \mathrm{~mm}$ are mixed with water to form tailings slurry, which is sent to the thickener for concentration and then discharged into the sludge mud dump after the bauxite original ore washing treatment. The mud dump is a control project of the mine. In fact, in order to prevent pipeline blockage, the water content of newly dredged mud can reach more than $300 \%$ due to long distance and large span of pipeline transportation [3]. The consolidation degree of mud in the mud dump is affected by many factors, including mineral composition, initial water content, and whether the mud is in the state of

\footnotetext{
${ }^{1}$ Zhiqiang $\mathrm{Wu}$, State Key Laboratory of Hydrology-Water Resources and Hydraulic Engineering, Nanjing 210029, China; E-mail: zqwu@nhri.cn.
} 
flowing [4]. It is difficult to drain and consolidate high-water content mud under natural conditions [5]. The bearing capacity of surface layer in the dump will be extremely low after several or even more than ten years [6-8].

A large number of researches on the application of slime for preparation of cement materials have been carried out, but most of them stayed in the experimental stage due to economic reasons [9, 10]. Domestic scholars have carried out comprehensive experimental researches on the application of slime as new wall material [11], ceramic material, slime glass material, road building material and backfilling material, combined with the specific conditions of China [12]. However, the premise for further resource utilization is the effective separation of water and tailing particles in slime. Unfortunately, water characteristics of bauxite mine slime still needs to be further studied. In view of this, this study carried out the water property test and, analysed the water composition under different initial states. Small-scale slurry-water separation model tests were also carried out, with the surface settlement and, amount of water pumped from the slime under the controlled vacuum load application process recorded accurately. The research results can provide a reference to the dematerialization and recycling utilization.

\section{Material and Test Method}

\subsection{Soil Specimen}

The test specimen was a kind of mine slime from bauxite ore washing, collected from one of the mud dumps located in Debao County, Guangxi Province. The design mine slime storage capacity was $2848 \times 10^{4} \mathrm{~m}^{3}$, and the rockfill dam was designed at $59.7 \mathrm{~m}$. There were about $2500 \times 10^{4} \mathrm{~m}^{3}$ high-water content bauxite mine slime in the dump. Slime was in the state of flowing after miles of pipeline transportation for, long years. The mine slime was composed of more than 12 minerals according to X-ray diffraction and electronic microprobe analysis. And the major mineral phases were gibbsite, goethite, kaolinite, diaspore, clinochlore, pyrophyllite, hematite, and quartz, which accounted for $93.4 \%$ of total minerals. $\mathrm{Al}_{2} \mathrm{O}_{3}, \mathrm{SiO}_{2}$, and $\mathrm{Fe}_{2} \mathrm{O}_{3}$ accounts for $93.5 \%$ of all oxides according to the fluorescence spectrum. Detailed mineral type and content are shown in table 1 .

Table 1. Mineral type and content of bauxite mine slime.

\begin{tabular}{lll}
\hline Mineral name & $\mathrm{Chemical} \mathrm{formula}$ & Percentage \\
\hline Quartz & $\mathrm{SiO}_{2}$ & 3.6 \\
Gibbsite & $\mathrm{Al}_{(\mathrm{OH})_{3}}$ & 32.2 \\
Rutile & $\mathrm{TiO}_{2}$ & 2.0 \\
Hematite & $\mathrm{Fe}_{2} \mathrm{O}_{3}$ & 4.1 \\
Diaspore & $\mathrm{AlOOH}$ & 9.5 \\
Portlandite & $\mathrm{Ca}(\mathrm{OH})_{2}$ & 0.6 \\
Goethite & $\mathrm{FeOOH}$ & 19.8 \\
Illite & $\left(\mathrm{K}, \mathrm{H}_{3} \mathrm{O}\right)(\mathrm{Al}, \mathrm{Mg}, \mathrm{Fe})_{2}(\mathrm{Si}, \mathrm{Al})_{4} \mathrm{O}_{10}\left[(\mathrm{OH})_{2},\left(\mathrm{H}_{2} \mathrm{O}\right)\right]$ & 2.1 \\
Clinochlore & $(\mathrm{Mg}, \mathrm{Fe}) 5 \mathrm{Al}(\mathrm{Si} 3 \mathrm{Al}) \mathrm{O} 10(\mathrm{OH})_{8}$ & 9.4 \\
Vermiculite & $(\mathrm{Mg}, \mathrm{Fe}, \mathrm{Al})_{3}(\mathrm{Al}, \mathrm{Si})_{4} \mathrm{O}_{10}(\mathrm{OH})_{2} \cdot 4 \mathrm{H}_{2} \mathrm{O}$ & 0.2 \\
Pyrophyllite & $\mathrm{Al}_{2} \mathrm{Si}_{4} \mathrm{O}_{10}(\mathrm{OH})_{2}$ & 4.9 \\
Kaolinite & $\mathrm{Al}_{2} \mathrm{Si}_{2} \mathrm{O}_{5}(\mathrm{OH})_{4}$ & 9.9 \\
\hline
\end{tabular}


The soil specimen used in this test was collected from the surface layer without any impurities. According to automatic laser granularity analysis data, the high-water content mine slime was composed of $80.44 \%$ of clay particles, $19.37 \%$ of silt particles, and $0.19 \%$ of fine sand particles. The results showed that the mine slime was in liquid state with average water content of $281.9 \%$. Wet density and specific gravity were about $1.184 \mathrm{~g} / \mathrm{cm}^{3}$ and 2.89 respectively. Main index of physical mechanics of the slime are shown in table 2.

Table 2. Main index of physical mechanics of the slime.

\begin{tabular}{ll}
\hline Parameters & Character value \\
\hline Liquid limit, LL (\%) & 78.4 \\
Plastic value, PL (\%) & 27.1 \\
Liquidity index, LI & 4.97 \\
Clay particle $(\%)$ & 80.44 \\
Silt particle $(\%)$ & 19.37 \\
Sand particle $(\%)$ & 0.19 \\
Unit weight, $\gamma_{\mathrm{t}}\left(\mathrm{g} / \mathrm{cm}^{3}\right)$ & 1.184 \\
Water content, $w(\%)$ & 281.9 \\
State and color & Liquid state, yellow brown \\
\hline
\end{tabular}

\subsection{Testing Devices and Methodology}

\subsubsection{Water Existing Form Test}

Generally, water in bauxite mine slime can be divided into free water, bound water and hydration water. And the physical property is mainly affected by free water, bound water and their proportional relational relationship. The vapor pressure and density of bound water is different from free water due to its interaction with solid particles. Many methods can be used to test the bound water, including thermal drying method, dilatometric method, centrifugal separation method, and thermo-gravimetricdifferential thermal analysis method, etc. Hitachi high speed centrifuge was employed in this study.

The procedure was as follows: first, set rational speed, temperature and, rotation time parameter, then weight up the centrifuge rotor used in this study, and fill the rotor with test slime in three layers brought back from the engineering site. The whole filling process should be rapid, and the rotor should be immediately covered after filled with slime to avoid water evaporation caused by sample loading. Put the rotor with soil into the centrifuge, and balance weight in the experiment to keep rotor balance during the test.

\subsubsection{Soil-Water Separation Model Test}

The model box shown in figure 1. adopted in this test was made of organic glass with a size of $400 \times 180 \times 400 \mathrm{~mm}$. Three $400 \mathrm{~mm}$ long measuring tapes were pasted on the outside surface of the model box to measure the specimen settlement. The drainage used in this mode test was porous plastic tube with a diameter of $10 \mathrm{~mm}$. And the drainage was wrapped with filtration cloth to prevent soil particles from entering the drainage during the test. One end of the drainage was embedded in the soil, while the other end was fixed in a water collecting bottle. Water drained from the slime would be 
collected to the bottle through pipeline. Water weight was weighted by the electronic scale at the bottom of the collecting bottle. Suitable vacuum pressure was controlled by the valve on the pipeline and vacuum pump.

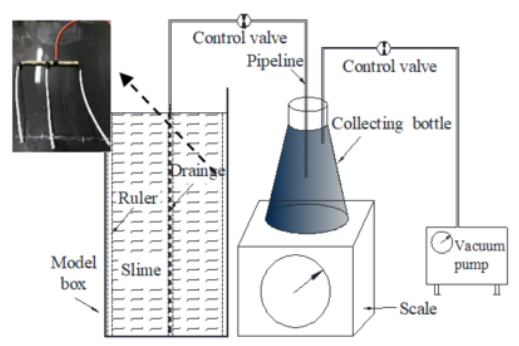

Figure 1. Centrifuge rotor and soil specimen.

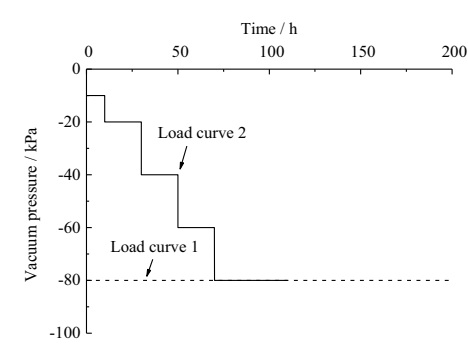

Figure 2. Vacuum loading Process.

Soil in the test was a kind of bauxite mine slime brought back from the field, and its main physical and mechanical parameters were listed in table 1 . The slime was fully stirred and the initial water content was $281.9 \%$ before the model test. The drainage was placed in he designed position in advance and the slime was slowly poured into the model box until the height reached $380 \mathrm{~mm}$. A plastic bag was bonded at the top mouse of the model box to ensure the vacuum in the process of vacuum loading. The loading process is shown in figure 2 .

\section{Test Results}

\subsection{Water Existing Form}

The $\mathrm{pF}$ value, the soil-water suction potential index, was used to classify water as free water, bound water and hydration water. And it's widely accepted that there is a liner relationship between water content and $\mathrm{pF}$ when $\mathrm{pF}$ value ranges from 2 to 4 . When $\mathrm{pF}$ value is lower than 3.8 , the water is free water. When $\mathrm{pF}$ lies between 3.8 and 7.0, the water is bound water. When $\mathrm{pF}$ value is higher than 7.0, the water is hydration water, but it is not within the scope of this study. The test curves of water content and $\mathrm{pF}$ value are shown in figure 3 to figure 4.

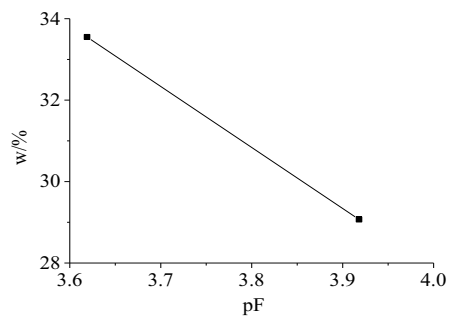

(a)

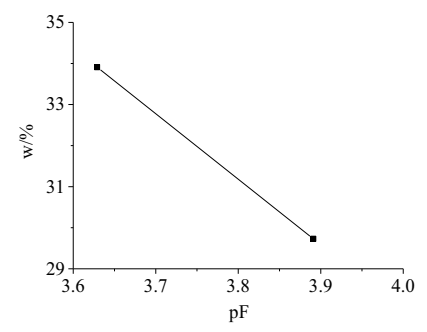

(b)

Figure 3. Relationship between water content and $\mathrm{pF}$ of sample 1 . 


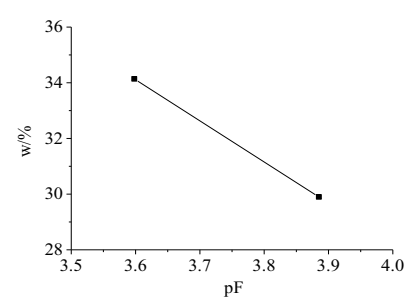

(a)

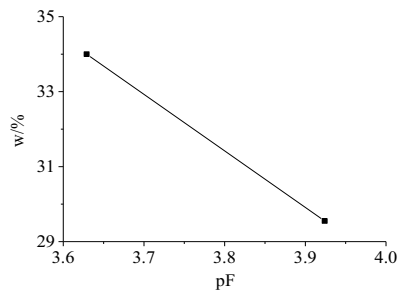

(b)

Figure 4. Relationship between water content and $\mathrm{pF}$ of sample 2.

The test curves demonstrated that the higher the $\mathrm{pF}$ value, the lower the water content. It can be seen that the water content was $33.35 \%$ when $\mathrm{pF}$ value was 3.619 , and water content was $29.07 \%$ when $\mathrm{pF}$ value was 3.918 as shown in figure 3 (a). The water content was $33.91 \%$ when $\mathrm{pF}$ value was 3.629 , and water content was $29.73 \%$ when $\mathrm{pF}$ value was 3.891 as shown in figure 3 (b). It can be seen that the water content was $34.14 \%$ when $\mathrm{pF}$ value was 3.598 , and water content was $29.90 \%$ when $\mathrm{pF}$ value was 3.885 as shown in figure 4 (a). The water content was $34.00 \%$ when $\mathrm{pF}$ value was 3.629 , and water content was $29.55 \%$ when $\mathrm{pF}$ value was 3.924 as shown in figure 4 (b).

\subsection{Soil-Water Separation Test Results}

\subsubsection{Single Vertical Drainage Body}

One porous plastic tube wrapped with filtration cloth with a diameter of $10 \mathrm{~mm}$ was positioned vertically in the model box, and it was used as drainage body in the experiment. The soil-water separation test results under load curve 1 (figure 2) are shown in figure 5 . As it can be seen from the spot and line curve, the surface settlement and water drained from the slime through pipeline increased with the application of vacuum load. Further analysis showed that the increasing rate of the settlement and drained water was much higher within the initial 40 hours, but slowed down afterwards. And eventually the curve reached a plateau. The settlement was $112.9 \mathrm{~mm}$, and the weight of the water pumped from the slime was $15.16 \mathrm{~kg}$. The slime volume decreased by $29.7 \%$, and the water content decreased from $281.9 \%$ to $103.2 \%$.

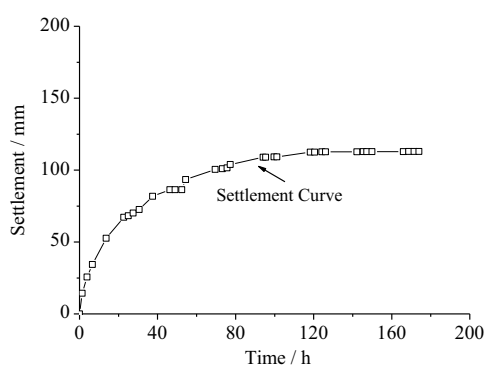

(a)

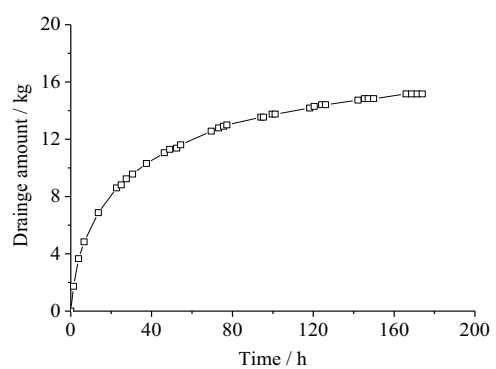

(b)

Figure 5. Settlement \& Drainage amount with time under load curve 1. 
The soil-water separation test results with one vertical drainage body under load curve 2 (figure 2) are shown in figure 6. The settlement first increased, then declined and kept stable finally, similar to changes of water pumped to the slime. Detailed analysis of experimental data indicated that water was drained rapidly from the slime in the initial 90 hours and then the increasing rate slowed down. The surface settlement was $232.6 \mathrm{~mm}$, and the weight of the water pumped from the slime was $18.51 \mathrm{~kg}$ according to recorded experimental data. Compared with the initial state, the slime volume decreased by $61.2 \%$, and the water content decreased from $281.9 \%$ to $63.2 \%$.

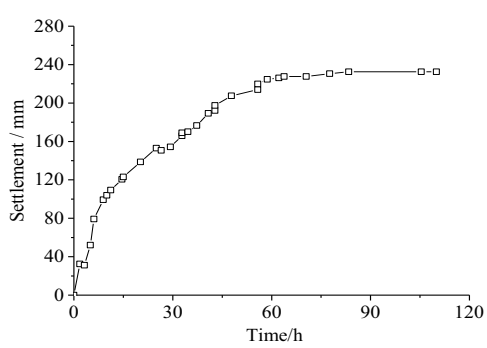

(a)

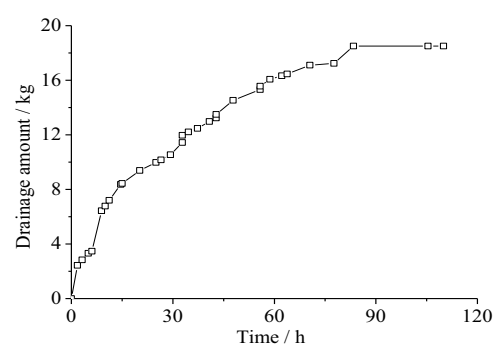

(b)

Figure 6. Settlement \& Drainage amount with time under load curve 2.

Comparison of the two groups of settlement and drained water amount data suggests that, the process of soil-water separation is strongly affected by vacuum loading process.

\subsubsection{Three Vertical Drainage Bodies}

Three porous plastic tubes were used as drainage body in the model test under two vacuum loading processes shown in the previous chapter in figure 2 . Three tubes adopted in this test were parallel and equidistant from each other in the horizontal direction and they were vertically placed in the slime. The tubes were wrapped with filtration cloth and finally connected with the vacuum pipeline the same as in the previous experiment. Curves in figure 7 showed that high increasing rate in initial stage under load curve 1, to be more specific, within the first 45 hours, the settlement was $212.2 \mathrm{~mm}$, and the pumped from the slime weighted $17.54 \mathrm{~kg}$. The slime volume decreased by $55.8 \%$, and the water content decreased from $281.9 \%$ to $75.1 \%$.

The final slime water content may decrease from $103.2 \%$ to $75.1 \%$ under the same loading pattern with the number of drainage body increased to three, when comparing figure 5 with figure 7 . And the volume changes due to pumping rose from $29.7 \%$ to $55.8 \%$ at the same time.

Test results under load curve 2 in figure 2 are shown in figure 8 . It can be concluded from figure 8 (a) that the surface settlement increased rapidly in the initial 30 to 40 hours, while the increasing trend slowed down until the end of the test. And the change regularities of drainage water amount share similar properties with surface settlement. The final amount of water pumped weighted $19.4 \mathrm{~kg}$. By calculation, the volume decreased by $55.5 \%$, and the water content decreased from $281.9 \%$ to $53.7 \%$. 


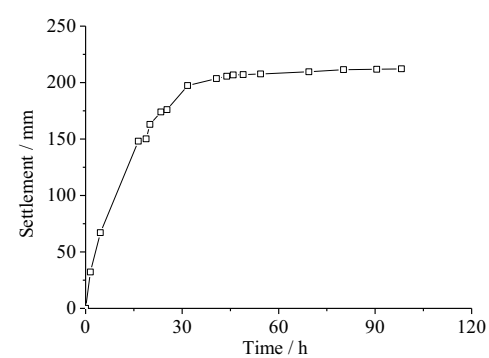

(a)

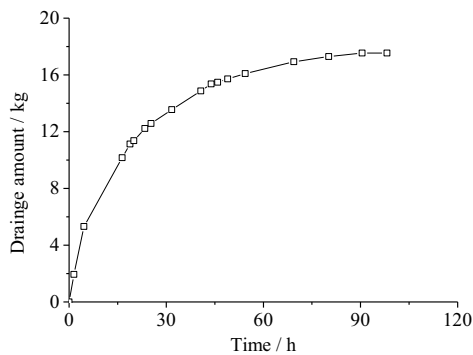

(b)

Figure 7. Settlement \& Drainage amount with time under load curve 1 (three drainage).

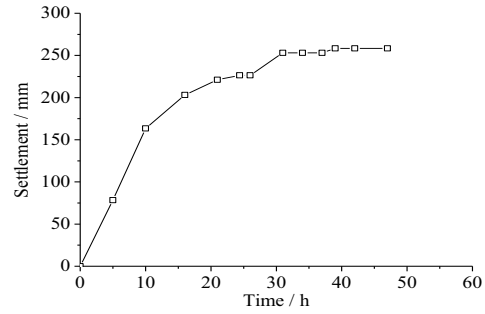

(a)

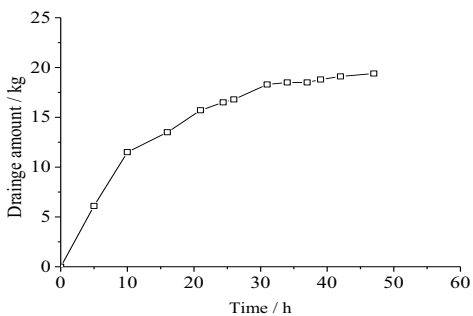

(b)

Figure 8. Settlement \& Drainage amount with time under load curve 2 (three drainage).

\section{Discussion}

Figure 5 to figure 8 give the soil-water separation test results under vacuum loading with different number of drainage bodies. It takes 180 hours to decrease the water content from $281.9 \%$ to $103.2 \%$ under common vacuum loading process, while it takes only about 120 hours for the slime to decrease to $61.2 \%$. This means controlling the loading process can dramatically shorten the time needed to separate soil particles from water. With the increase of drainage paths, time required will be further shortened. It takes only about 50 hours for the water content decreased from $281.9 \%$ to $53.7 \%$. It can be summarized as follows: 1) vacuum preloading can be used to accelerate the soilwater separation process; 2) water content can be decreased to less than $55 \%$ by increasing the drainage paths within 50 hours.

\section{Conclusion}

This study carried out laboratory and model test of bauxite mine slime collected from Debao County, Guangxi Province. The comprehensive characteristics, water existing form and soil-water separation property were studied in details. Based on this study, the following conclusions can be drawn:

(1) The soil-water suction potential $\mathrm{pF}$ can be used to classify bound water and free water. Indoor high-speed centrifuge was employed in this study at the 
manufacturing centrifugal field. Free water accounted for $90 \%$, while bound water accounted about only $10 \%$ of total water in the bauxite mine slime.

(2) Vacuum preloading can be used to accelerate the soil-water separation process. A transition from liquid state to plastic state takes only about 50 hours under the controlled vacuum loading process.

(3) The bauxite mine slime water content can be decreased to less than $55 \%$ by increasing the drainage paths. Model tests indicated that increasing the drainage path from one to three may make the water decreased from $281.9 \%$ to $53.2 \%$.

\section{Acknowledgments}

This study has been supported by the Central Public-interest Scientific Institution Basal Research Fund grant funded by the Chinese government (NO. Y32002, NO. Y32003, NO. Y921011). This study has also been supported by a grant from Technology Demonstration Project of China's Ministry of Water Resources (SF-202109) and from Transportation Science and Technology Project of Jiangsu Province. These supports are greatly appreciated. The authors also want to thank those who provided technical support in the laboratories from the State Key Lab of Hydrology-Water Resources and Hydraulic Engineering and Department of Civil Engineering, Nanjing Hydraulic Research Institute.

\section{References}

[1] Du CX, Peng ZB, Yang CD, Cen LQ and Chen A. Experimental study of solidification technology of the bauxite mine slime. Journal of Engineering Geology. 2006 Jan; 14(1): 117-21.

[2] Chen ShY, Li MY and Xie F. Accumulation type Bauxite ore washing mud centrifuge dehydration experiment research. Nonferrous Metals. 2016 Mar; 2: 43-6.

[3] Lei HY, Li ChY, Liu JJ and Wang L. Experimental study and numerical simulation of alternating vacuum preloading method for strengthening hydraulic fill super soft soil. Chinese Journal of Rock Mechanics and Engineering. 2019 Oct; 38(1): 1-14.

[4] Yin WZh. Latest developments of tailings stockpiling technology and equipment. Metal Mine. $2016 \mathrm{Jul} ; 7:$ 78-83.

[5] Li YT and Zhang YL. Practices of efficient high frequency dewatering screen technology in dry discharge of tailings. Gold. 2016 May; 37(5): 66-71.

[6] Li JQ, Ou XD, Yang JW and Liao YF. An experimental study on self-weight consolidation of the red mud tailings placed in karst regions. Journal of Guangxi University: Nat. Sci. Ed. 2012 Feb; 37(1): 152-9.

[7] Wang WF. The Application of horizontal belt - type filter in reclamation of dry stockpile of tailings. Mining Engineering. 2018 Feb; 16(1): 41-4.

[8] Lei HY, Liu YN, Feng ShX and Liu JJ. Model tests and numerical simulations of newly sheet-free vacuum preloading method for ultra-soft dredger fills. Chinese Journal of Geotechnical Engineering. 2017 Oct; 39(s2): 189-93.

[9] Hou JF and Liu WB. Experimental analysis and comparison of consolidation of ultra-soft soil under electro-osmotic and vacuum preloading-electro-osmosis. China Harbour Engineering. 2018 Feb; 38(2): 30-4.

[10] Chen $\mathrm{YX}$ and An ShL. Study on $\mathrm{Fe}-\mathrm{Al}_{2} \mathrm{O}_{3}$ composites prepared from bayan obo iron concentrate and bauxite. Journal of Inner Mongolia University of Science and Technology. 2021 Jan; 40(1): 45-51.

[11] Lu ZhQ, Xia JP, Zhang ZhSh and Liu F. Technological study of producing low temperature ceramic and foam material with tailing of flotation bauxite. Bulletin of The Chinese Ceramic Society. 2010 Oct; 29(5): 1133-8.

[12] Gao W, Zhang Q and Li Sh. Roasting desulfurization-alkaline leaching desilication of high - sulfur bauxite. Hydrometallurgy of China. 2021 May; 40(3): 202-6. 